\title{
Laparoscopic cholecystectomy during COVID-19 pandemic- Retrospective analysis of tertiary care centre
}

\author{
Uttam Laudari', Rosi Pradhan ${ }^{2}$, Dibesh Shrestha', Bibek Timilsina', Suhail Sapkota', Dimindra Karki ${ }^{3}$, \\ Suraj Lamichhane, ${ }^{4}$ Anuj Parajuli ${ }^{5}$ \\ 'Department of Surgery, Hospital for Advanced Medicine and Surgery, Dhumbarahi, Kathmandu, Nepal \\ ${ }^{2}$ Department of Anaesthesiology, KIST Medical College, Imadol, Lalitpur, Nepal \\ ${ }^{3}$ Department of Surgery, Patan Academy of Health Sciences, Lalitpur, Nepal. \\ ${ }^{4}$ Department of Anaesthesiology, Hospital for Advanced Medicine and Surgery, Dhumbarahi, Kathmandu, Nepal. \\ Department of Surgery, Kathmandu Medical College, Sinamangal, Kathmandu, Nepal.
}

\begin{abstract}
INTRODUCTION

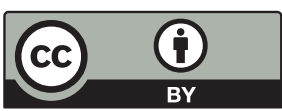

This work is licensed under a Creative Commons Attribution 4.0 Unported License.

Laparoscopic cholecystectomy is the most commonly performed general surgical procedure. During the COVID-19 pandemic, general recommendation worldwide is to postpone elective surgeries as far as possible to decrease the resource utilization and also aerosol-related transmission among hospital staff and patients. We conducted this study to see the burden of gallbladder disease, their management and outcomes of all patients who presented to our centre during first wave of COVID-19 pandemic.
\end{abstract}

\section{METHODS}

We conducted a retrospective analysis of all patients who underwent laparoscopic cholecystectomy at the Hospital for Advanced Medicine and Surgery (HAMS) after the commencement of strict lockdown in the first wave of the COVID-19 pandemic. Ethical approval for the study was taken from Nepal Health Research Council. All the surgeries were performed as per HAMS interim policy for infection prevention and control during the COVID-19 pandemic. Data were extracted from the discharge sheet and outcomes in terms of duration of hospitalization, morbidity, mortality, and COVID -19 infection among patient and operating team staff after surgery were assessed.

\section{RESULTS}

Out of 110 cases operated for gallbladder disease, 90 patients were included in the study with complete data. The most common presentations were dyspepsia (28) and biliary colic (22). Patients were managed with laparoscopic cholecystectomy (79), percutaneous cholecystostomy (4), laparoscopic subtotal cholecystectomy (5), open cholecystectomy (1). The median duration of hospitalization 22 hours. There was no COVID-19 transmission among staff and patients.

\section{CONCLUSIONS}

Laparoscopic cholecystectomies are feasible during COVID-19 pandemic and safely performed following infection prevention guidelines. It can be still be performed in day case basis to decrease the bed occupancy and avoiding crowd in hospitals.

\section{KEYWORDS}

COVID-19; Cholecystectomy; Laparoscopic surgeries.

\section{INTRODUCTION}

Laparoscopic cholecystectomy (LC) is the gold standard treatment for symptomatic gallbladder diseases. (1) During the COVID -19 pandemic WHO recommended postponement of all elective surgeries. (2) Postponement of uncomplicated symptomatic cholelithiasis may increase the gall stone-related complication and increase morbidity, mortality and economic burden. ${ }^{(1)}$

Though postponement of elective surgeries helps to reduce utilization of necessary resources during the pandemic, management and prevention of gall stones and related

\section{*Corresponding Author}

Dr.Uttam Laudari, Hospital for Advanced medicine and surgery, Dhumbarahi, Kathmandu, Nepal. Email: youttam@hotmail.com. Phone: +977-9841259423 
complications during the pandemic must be scrutinized to decrease the burden on the national level. (1) The Royal College of Surgeons recommended considering laparoscopy only in selected individual cases, where the clinical benefit to the patient substantially exceeds the risk of potential viral transmission to the surgeons and the theatre teams in that particular situation. (1)

We conducted this study to evaluate the burden of gallbladder disease at our centre after detection of the first COVID -19 in Nepal ${ }^{(3)}$, their management, and outcomes during the study period.

\section{METHODS}

We conducted a retrospective analysis of all LC during the study period after ethical clearance from the Nepal Health Research Council (ERB protocol 286/2021 P), Kathmandu, Nepal. Our hospital is a 100 bedded tertiary care referral centre and has been treating both COVID-19 and nonCOVID-19 patients during pandemic. All the surgeries were performed as per HAMS interim policy for infection prevention and control during the COVID-19 pandemic, formed on June 16, 2020. (Figure 1 and Figure 2). Patients with symptomatic gallstone and polyp were investigated via the outpatient department (OPD). Patients with acute cholecystitis and its sequelae were admitted, and LC was performed the next day. Mild acute biliary pancreatitis were treated with LC after 48 hours of admission. For moderately severe and severe biliary pancreatitis, interval cholecystectomy was done. LC after Endoscopic Retrograde Cholangiopancreatography (ERCP) was done 48 hours post-procedure after ruling out ERCP-related complications. After the pre-anesthetic assessment, all the patients were ensured to have negative PCR COVID-19 reports. Patients were admitted two hours before surgery in non-COVID designated wards for elective surgeries. Informed consent was taken; potential complications, chances of conversion to open procedure were explained. All the patients were kept nil per oral (NPO) for six hours prior to surgery. All the operation theatre staff used N95 masks and face shields during surgery. Negative pressure theatre was used in case of suspicious cases. $10 \%$ povidone-iodine was used for painting. All patients also received a single intravenous dose $(750 \mathrm{mg})$ of cefuroxime at induction of anaesthesia. Total intravenous general anaesthesia was provided with propofol infusion, rocuronium, fentanyl, and sevoflurane with oxygen. An intravenous infusion of 1-2 L of a crystalloid solution was given to all patients during the operation. For patients with comorbidities, optimization was done accordingly. Pregnant patients were operated on during the second trimester. The same group of experienced surgeons performed all the surgeries. All the patients underwent fourport laparoscopic cholecystectomy with carbon dioxide pneumoperitoneum of $12-15 \mathrm{mmHg}$. Subhepatic drain was placed in case of difficult dissection, intraoperative bleeding, complicated gallbladder and bile leaks. Ondansetron injection was given to patients at the operation theatre and shifted to the postoperative ward, then feeding started. Most patients were discharged the next day if discharge criteria were met. High-risk patients requiring monitoring were all shifted to ICU. Data were extracted from the discharge sheet containing age, gender, presenting complaints, American Society of Anaesthesiology (ASA) grade, type of anaesthesia, the reason for conversion to open cholecystectomy, number of subtotal cholecystectomies and bailout procedures, complications, duration of hospital stay in hours, readmission after discharge, morbidity and mortality, preoperative and postoperative COVID-19 status of patients and hospital staffs. Statistical Package for Social Sciences (SPSS, Inc., Chicago, Illinois) version 16.0 was used for statistical analysis. Continuous data are presented as mean \pm Standard Deviation (SD). Categorical data are presented as proportions.

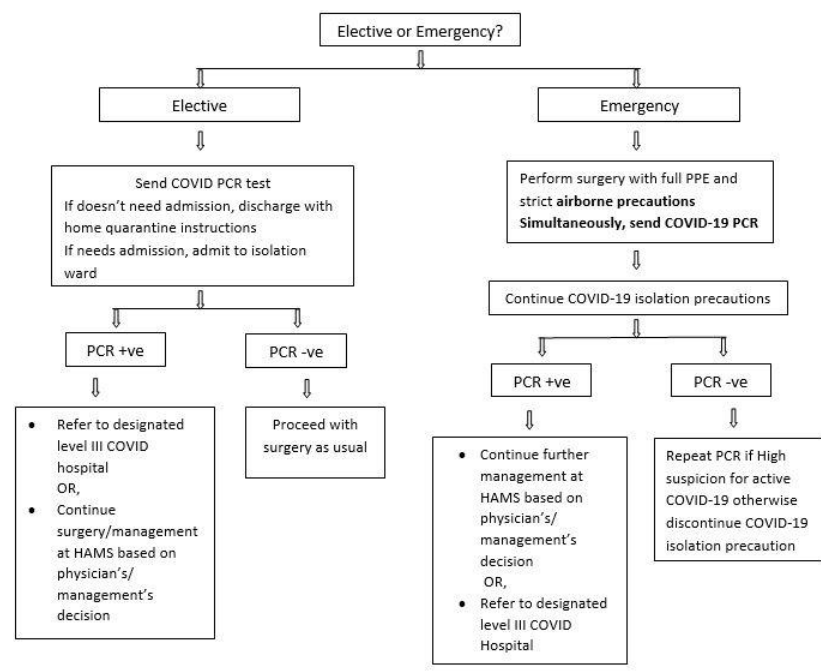

Figure 1- Guidelines according to HAMS interim policy for cases with high COVID risk needing surgery

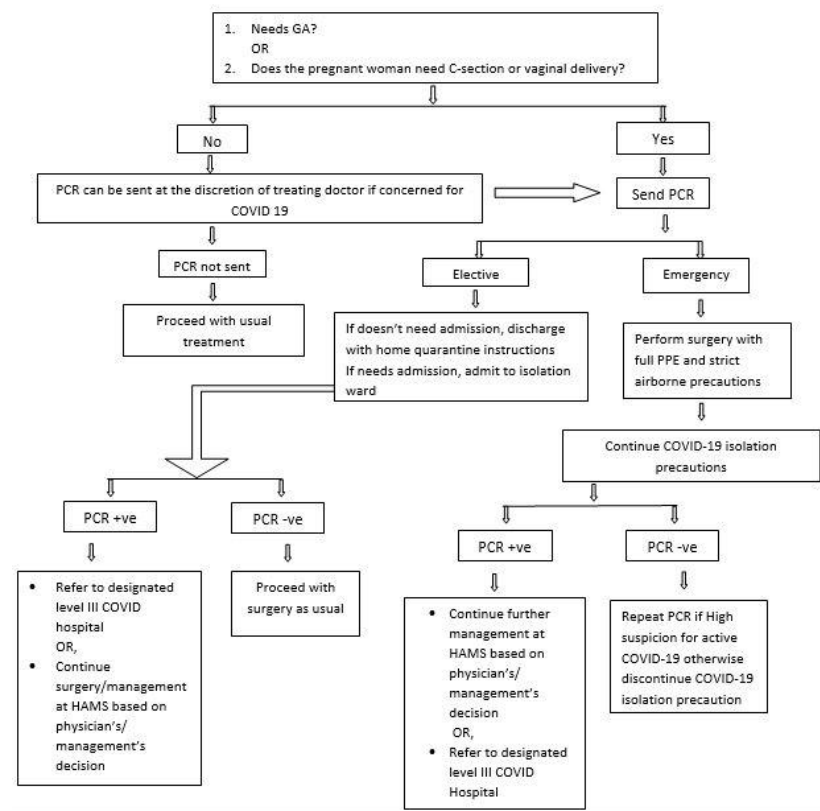

Figure 2- Guidelines according to HAMS interim policy for cases with low COVID risk needing surgery 


\section{RESULTS}

Out of 110 cases operated for gallbladder disease, 90 patients were included in the study with complete data. Demography, indication for surgery and complications are shown in Table 1 and Table 2. The most common presentations were dyspepsia $(n=28)$ and biliary colic $(n=22)$. Two patients were operated on in the second trimester of pregnancy, one for mild acute biliary pancreatitis and the other for recurrent cholecystitis during the first trimester. Two patients were found to have incidental carcinoma gallbladder, one of which underwent extended cholecystectomy, and another patient had omental metastasis. Out of 90 patients, five cases of acute cholecystitis underwent bailout procedure in the form of subtotal cholecystectomy. Two patients underwent laparoscopic converted to open cholecystectomy; one was for a shrivelled gallbladder with Strasberg D bile duct injury managed with primary repair and was discharged on the fifth postoperative day the other was managed with open cholecystectomy for sealed gallbladder perforation. Two patients were readmitted; the first case was readmitted on the second postoperative day for the post cholecystectomy syndrome. She underwent diagnostic laparoscopy, peritoneal lavage, duct of Luschka was clipped for leakage, and drain was placed. She was discharged on the third postoperative day. The other patient was readmitted for post LC pancreatitis who was managed conservatively.

Overall treatment outcome and complications are shown in Table 4. No surgery-related mortality was seen during the study period. During the initial period of lockdown, two patients of acute calculous cholecystitis were managed with percutaneous cholecystostomy, followed by interval LC. Two patients with acalculous cholecystitis were managed with percutaneous cholecystostomy and drain placement. One patient who had a COVID infection 1.5-month prior to surgery developed postoperative non-STEMI, was managed in the intensive care setting for five days, and was discharged. Among patients with biliary pancreatitis, 1 had severe pancreatitis, and was managed with interval cholecystectomy. The median day of hospitalization was 24 hours, ranging from 15 hours to 260 hours. Patients with prolonged hospital admission were those with difficult cholecystectomies with drain placement and postoperative cardiorespiratory issues.

Table 1: Demographics parameter of patients during study period

\begin{tabular}{|l|l|}
\hline \multicolumn{1}{|c|}{ Age in years } & Frequency \\
\hline$<20$ & 1 \\
\hline $20-39$ & 22 \\
\hline $40-59$ & 43 \\
\hline $60-80$ & 24 \\
\hline
\end{tabular}

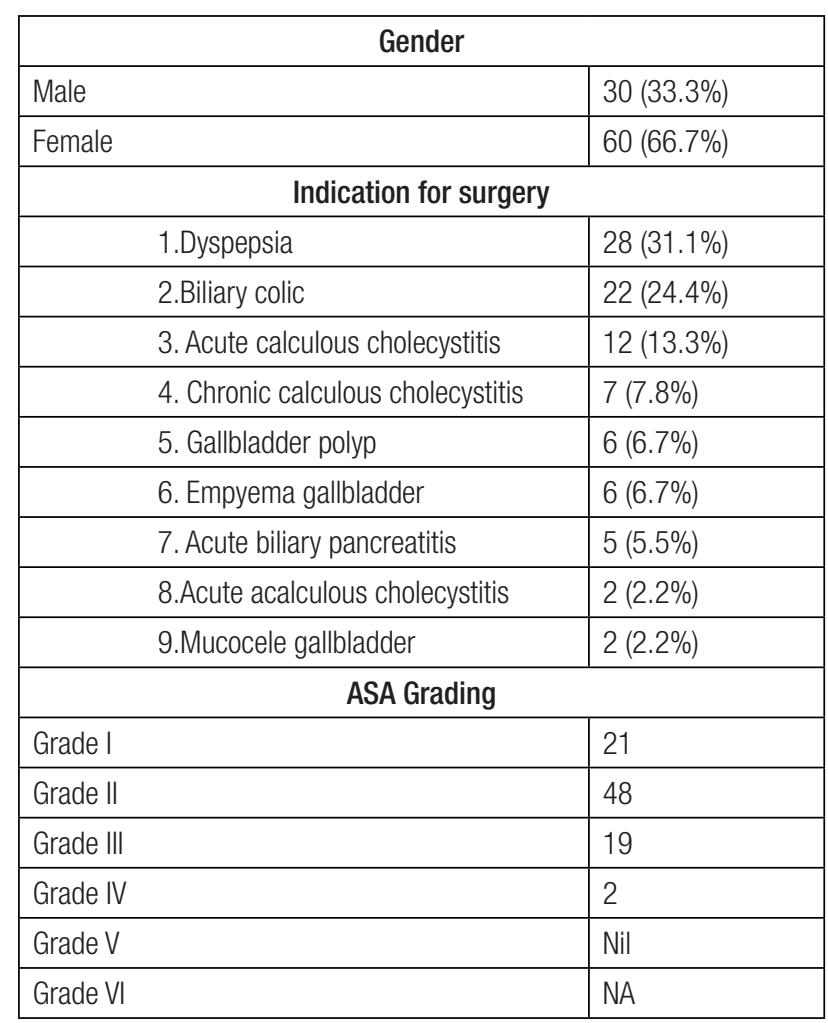

Table 2. Type of surgical procedures among study population

\begin{tabular}{|l|l|}
\hline \multicolumn{1}{|c|}{ Types } & \multicolumn{1}{c|}{ Frequency } \\
\hline Laparoscopic cholecystectomy & 79 \\
\hline Percutaneous cholecystostomy & 4 \\
\hline Subtotal cholecystectomy & 5 \\
\hline Open cholecystectomy & 1 \\
\hline Extended cholecystectomy & 1 \\
\hline
\end{tabular}

Table 3. Associated comorbidities in study population

\begin{tabular}{|l|l|}
\hline \multicolumn{1}{|c|}{ Associated conditions } & Frequency \\
\hline Cardiovascular & \\
Systemic Hypertension & 27 \\
CAD & 3 \\
Valvular heart disease (Prosthetic Valves) & 2 \\
Arrhythmias & \\
Atrial Fibrillation & 2 \\
Complete Heart block (with a pacemaker in situ) & 1 \\
Supraventricular tachycardia & 1 \\
\hline Thyroid disorder & 6 \\
\hline Diabetes Mellitus & 4 \\
\hline Neurological disorder (seizure and stroke) & 2 \\
\hline Chronic kidney disease & 1 \\
\hline Pregnancy & 2 \\
\hline
\end{tabular}

Table 4. Complications and outcomes of patients in study population

\begin{tabular}{|l|l|l|l|}
\hline \multicolumn{1}{|c|}{ Complications } & & Frequency & $\begin{array}{c}\text { Clavien- } \\
\text { Dindo grade }\end{array}$ \\
\hline $\begin{array}{l}\text { Surgical site } \\
\text { infection }\end{array}$ & Superficial & 4 & Grade I \\
\cline { 2 - 4 } & Deep & 1 & Grade II \\
\hline
\end{tabular}




\begin{tabular}{|l|l|l|l|}
\hline \multirow{2}{*}{ Biliary Leak } & Strasberg A & 1 & Grade IIIB \\
\cline { 2 - 4 } & Strasberg D & 1 & Grade I \\
\hline $\begin{array}{l}\text { Type 3 respiratory } \\
\text { failure }\end{array}$ & Basal atelectasis & 1 & Grade I \\
\hline $\begin{array}{l}\text { Myocardial } \\
\text { infarction }\end{array}$ & & 1 & Grade IV \\
\hline $\begin{array}{l}\text { Conversion to open } \\
\text { cholecystectomy }\end{array}$ & & 1 & Grade I \\
\hline Readmission & & 2 & $\begin{array}{l}\text { Grade I and } \\
\text { Grade II }\end{array}$ \\
\hline
\end{tabular}

\section{DISCUSSION}

Our finding shows that laparoscopic cholecystectomy is feasible during the COVID-19 pandemic without any transmission among hospital staff and patients. Most of the patients had less than 24-hour hospital admission. Admitting a patient two hours before surgery and discharging the next day helped us expedite bed availability and decrease crowding in the hospital during the pandemic. Though ASA I and II patients are predominant, ASA III and IV patients were also in significant number during study period. One patient had Calvien-Dindo Grade IV complication i.e., she had postoperative NSTEMI myocardial infarction and was managed in ICU.

Society of American Gastrointestinal and Endoscopic Surgeons (SAGES) recommended postponement of all elective surgical cases during the pandemic to minimize risk to patients and healthcare staff and minimize resources like ventilators, PPE, and beds. ${ }^{(1)}$ The Association of laparoscopic surgeons of Great Britain and Ireland recommended the use of laparoscopy for patient's benefit if all safety measures can be taken in the operating room. Some of the general recommendations from different societies are the use of closed-circuit smoke evacuation and ultralow particulate air filtration systems, low power setting of electrocautery, minimal use of energy devices, small port incisions, low CO2 pressure, pneumoperitoneum evacuation via filtration system, liberal use of suction devices, immediate evacuation of gas at the end of the procedure and reduced Trendelenburg time. ${ }^{(5)}$ There are still no absolute contraindications for laparoscopic surgical procedures, however, the use of appropriate PPE for operating theatre teams, smoke evacuations/ filtration systems have been recommended in the literature. ${ }^{(5)}$ During the initial lockdown period, all elective cholecystectomies were postponed. Patient flow in outpatients decreased substantially. Two cases of acute cholecystitis were managed with cholecystostomy. One pregnant patient who was in the first trimester was initially managed conservatively, and later underwent cholecystectomy during the second trimester. of the two cases of sealed gall bladder perforation, one was managed with cholecystostomy, followed by interval cholecystectomy, and the other underwent open cholecystectomy. All the other LC were done after the first wave of the pandemic was decreased.

Some considerations before resuming elective surgeries are - there should be a sustained reduction in the rate of new COVID-19 cases detection for at least 14 days and hospitals need to be well equipped with ICU and non-ICU beds, PPE, ventilators, and adequately trained staff. Hospitals should be available to protect staff and maintain patient safety. Hospitals should have a policy to address the requirement and frequency of testing. They should have adequate PPE and medical supplies. Staff should be trained on the proper use of PPE and establish a prioritization strategy appropriate to the immediate patient needs. Our hospital is a tertiary care multispecialty centre. ${ }^{(6)}$ (7) HAMS interim policy for infection prevention and control during COVID-19 pandemic was formed on June 16, 2020, that put forth guidelines on preoperative and pre-procedure COVID-19 screening, guidelines on PPE use, guidelines for operating on patients with high and low COVID risk. They also formed guidelines on treating patients for conservatively, staff quarantine and testing strategies.

Campanile et al., in their multi-society position statement, recommended $L C$ as the treatment of choice for cholecystitis during the COVID-19 pandemic, but the procedure should be carried out safely. They suggested using filters to remove virus particles, like ULPA (ultra-low particulate air) filters, to reduce the risk of virus diffusion in the operating theatre and ensure that patients continue to benefit from the advantages of laparoscopic surgery. ${ }^{(8)}$ However, in our setting, such a filter was not available. In those patients unfit for surgery, percutaneous transhepatic cholecystostomy may be considered after the failure of conservative therapy with antibiotics. ${ }^{(8,9)}$ In this study, four patients were managed with percutaneous cholecystostomy followed by LC. The benefit of laparoscopic surgery during the pandemic era is that it reduces length of hospital stay (1). In our study, all cases were admitted two hours before surgery; optimization and necessary investigations were done on OPD basis. A significant number of patients were discharged within 24 hours, highlighting the need for ambulatory surgery during and after the pandemic. These strategies can reduce the LOS, cost of treatment and reduce the burden of disease and long waiting lists in public hospitals in LMIC. ${ }^{(10)}$

\section{CONCLUSIONS}

Gall bladder disease is a common presentation in surgical department. Laparoscopic cholecystectomies can still be safely performed during COVID-19 pandemic after following strict infection prevention guidelines. They can be performed as day case surgery to reduce hospital stay and bed occupancy. 


\section{Nepal Mediciti Medical Journal}

\section{Conflict of Interest: None}

\section{ACKNOWLEDGEMENTS}

Dr. Prabin Bikram Thapa, Dr. Dhiresh Kumar Maharjan, Dr. Murari Raj Upreti

\section{REFERENCES}

1. Maria T, Angelico R, Parente A, Muiesan P, Group I, Al $Y$, et al. Global management of common, underrated surgical task during the COVID-19 pandemic: Gallstone disease - An international survery. Ann Med Surg [Internet]. 2020;57(July):95-102. PubMed | Full Text |DO|

2. Francis $N$, Dort J, Cho E, Feldman L, Keller D, Lim R, et al. SAGES and EAES recommendations for minimally invasive during COVID 19 pandemic. Surg Endosc 2020;34(6):2327-31. PubMed |Full Text| DOI

3. Thapa G, Nepal B. Laparoscopic Surgery in COVID-19 Era in a Tertiary Hospital in Nepal. Nepalese Medical Journal, 3(2), 356360. Full Text|DOI

4. Al-qahtani HH, Alam MK, Asalamah S, Akeely M, Ibrar M. Day-case laparoscopic cholecystectomy. Saudi Med J. 2015;36(1):46-51. PubMed | Full Text |DO|

5. Moletta L, Pierobon ES, Capovilla G, et al. International guidelines and recommendations for surgery during Covid-19 pandemic: A Systematic Review. Int J Surg. 2020;79:180-188. PubMed |Full Text| DOI

6. Joint Statement: Roadmap for Resuming Elective Surgery after COVID-19 Pandemic. Full Text

7. Six considerations for resuming surgeries after COVID-19. 1920. Full Text

8. Campanile FC, Podda M, Arezzo A, Botteri E, Sartori A, Guerrieri $M$, et al. Acute cholecystitis during COVID-19 pandemic: A multisocietary position statement. World J Emerg Surg. 2020;15(1):1-5. PubMed |Full Text| DOI

9. Barabino M, Piccolo G, Trizzino A, Fedele V, Ferrari C, Nicastro $V$, et al. COVID-19 outbreak and acute cholecystitis in a Hub Hospital in Milan: wider indications for percutaneous cholecystostomy. BMC Surg 2021;21(1):1-8. PubMed | Full Text |DO|

10. Matías-García B, Sánchez-Gollarte A, Quiroga-Valcárcel A, Mendoza-Moreno F, Mínguez-García J, Vera-Mansilla C, et al. Comparative analysis of management of acute cholecystitis during the SARS-CoV-2 coronavirus pandemic. MOJ Surg. 2021;9(2):35-8. Full Textl DOI 